University of Nebraska - Lincoln

DigitalCommons@University of Nebraska - Lincoln

Public Health Resources

Public Health Resources

2009

\title{
Children's Behavioral Traits and Risk of Injury: Analyses from a Case-Control Study of Agricultural Households
}

Kathleen F. Carlson

Polytrauma and Blast-Related Injuries QUERI, Center for Chronic Disease Outcomes Research, VA Medical Center (152/2E), One Veterans Drive, Minneapolis, MN

Susan G. Gerberich

Regional Injury Prevention Research Center, Division of Environmental Health Sciences, School of Public Health, University of Minnesota, MMC 807, 420 Delaware Street S.E., Minneapolis, MN

Bruce H. Alexander

Regional Injury Prevention Research Center, Division of Environmental Health Sciences, School of Public Health, University of Minnesota, MMC 807, 420 Delaware Street S.E., Minneapolis, MN

Ann S. Masten

Institute of Child Development, University of Minnesota, 51 East River Road, Minneapolis, MN 55455, USA

Timothy R. Church

Regional Injury Prevention Research Center, Division of Environmental Health Sciences, School of Public Health, University of Minnesota, MMC 807, 420 Delaware Street S.E., Minneapolis, MN

See next page for additional authors

Follow this and additional works at: https://digitalcommons.unl.edu/publichealthresources

Part of the Public Health Commons

Carlson, Kathleen F.; Gerberich, Susan G.; Alexander, Bruce H.; Masten, Ann S.; Church, Timothy R.; Shutske, John M.; Ryan, Andrew D.; and Renier, Colleen M., "Children's Behavioral Traits and Risk of Injury: Analyses from a Case-Control Study of Agricultural Households" (2009). Public Health Resources. 10. https://digitalcommons.unl.edu/publichealthresources/10

This Article is brought to you for free and open access by the Public Health Resources at DigitalCommons@University of Nebraska - Lincoln. It has been accepted for inclusion in Public Health Resources by an authorized administrator of DigitalCommons@University of Nebraska - Lincoln. 
Authors

Kathleen F. Carlson, Susan G. Gerberich, Bruce H. Alexander, Ann S. Masten, Timothy R. Church, John M. Shutske, Andrew D. Ryan, and Colleen M. Renier 


\title{
Children's behavioral traits and risk of injury: Analyses from a case-control study of agricultural households
}

\author{
Kathleen F. Carlson a,b,*, Susan G. Gerberich ${ }^{\text {b }}$, Bruce H. Alexander ${ }^{\text {b }}$, Ann S. Masten ${ }^{\text {c }}$, Timothy R. Church ${ }^{\text {b }}$, \\ John M. Shutske ${ }^{\mathrm{d}}$, Andrew D. Ryan ${ }^{\mathrm{b}}$, Colleen M. Renier ${ }^{\mathrm{e}}$ \\ a Polytrauma and Blast-Related Injuries QUERI, Center for Chronic Disease Outcomes Research, VA Medical Center (152/2E), One Veterans Drive, Minneapolis, MN 55417, USA

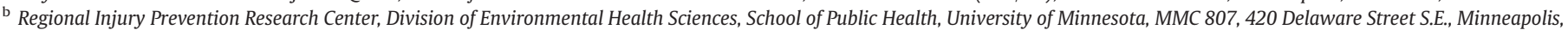 \\ MN 55455, USA \\ c Institute of Child Development, University of Minnesota, 51 East River Road, Minneapolis, MN 55455, USA \\ ${ }^{\mathrm{d}}$ College of Agricultural and Life Sciences, University of Wisconsin - Madison, 1450 Linden Drive, Madison, WI 53706, USA \\ e Division of Education and Research, St. Mary's Duluth Clinic Health System, 5AV2ME, 400 E. 3rd Street, Duluth, MN 55805, USA
}

\section{A R T I C L E I N F O}

Available online $\mathrm{xxxx}$

\section{Keywords:}

Agricultural injury

Injury

Youth

Behavior

Farm safety

\begin{abstract}
A B S T R A C T
Problem: Children on family agricultural operations have high risk of injury. The association between children's behavioral traits and their risk of injury is not well understood. Method: Data from the Regional Rural Injury Study-II were used to assess behavioral risk factors for injury to children ages six to $<20$ years. A total of 379 injury events (cases) and 1,562 randomly selected controls were identified. Adjusted odds ratios (OR) and 95\% confidence intervals (CI), calculated using logistic regression, were used to estimate injury risk in reference to behavioral traits. Results: Injury risks were greater for children with high levels of depressive symptoms ( $\mathrm{OR}=1.9, \mathrm{CI}=1.0-3.7)$ and aggression ( $\mathrm{OR}=1.6, \mathrm{CI}=0.9-2.7)$, and low levels of careful/cautious behavior $(\mathrm{OR}=1.8, \mathrm{CI}=1.1-2.9)$. Children with low levels of self-regulation had reduced risks $(\mathrm{OR}=0.4$, $\mathrm{CI}=0.2-0.8$ ). Discussion: Results suggest that children's behaviors affect their risk of agricultural injury. Additional research could elucidate mechanisms and inform interventions. Impact on industry: The development of multifaceted, sustainable approaches for prevention is necessary for this unique population. These findings suggest a need for interventions that incorporate specific behavior-related risk factors in the context of family farms and ranches.
\end{abstract}

\section{Problem}

Agriculture is among the most hazardous industries in the United States, with rates of fatal injuries more than nine times greater than all occupations combined (National Safety Council , 2007). Unlike other industrial settings, the overlap between occupational and household environments on agricultural operations contributes to high rates of pediatric mortality, morbidity, and disability among agricultural families (Goldcamp, Hendricks, \& Myers, 2004; Hendricks, Layne, Goldcamp, \& Myers, 2005; Rivara, 1997). Sociocultural characteristics of the rural agricultural population, such as the perceived economic (Kim \& Zepeda, 2004a,b) and developmental (Kim \& Zepeda, 2004a,b; Lee, Jenkins, \& Westaby, 1997) importance of children's agricultural work, are also important factors that contribute to these elevated rates.

\footnotetext{
* Corresponding author. Regional Injury Prevention Research Center, Division of Environmental Health Sciences, School of Public Health, University of Minnesota, MMC 807, 420 Delaware Street S.E., Minneapolis, MN 55455, USA. Tel.: +1 6124671421.

E-mail address: ferg0114@umn.edu (K.F. Carlson).
}

Exposures to specific environmental hazards, such as tractors, machinery, and various types of animals, have been shown to increase children's risk of injury on agricultural operations (Gerberich et al., 2001). Behavioral risk factors, however, have not been well characterized in this population. Prior research has shown behavioral traits, such as distractibility or impulsivity, to be positively associated with risk of injury among children (Bijur, Stewart-Brown, \& Butler, 1986; Jaquess \& Finney, 1994; Schwebel \& Plumert, 1999). Traits such as overactivity, inattentiveness, aggression, and impulsivity have been found to be independent risk factors for injury among people of all ages (Bijur et al., 1986; Davidson, 1987; Jaquess \& Finney, 1994; Wazana, 1997). How such behaviors might influence risk of agricultural injury among members of farm and ranch families is unknown.

In recent years, the study of behavioral risk factors has subsided in favor of a more resolute focus on environmental hazards and passive interventions. However, given that this approach has had limited success in the agricultural community (DeRoo \& Rautiainen, 2000; Hartling, Brison, Crumley, Klassen, \& Pickett, 2004), with its unique values and work traditions (Elder \& Conger, 2000), a multifaceted approach to children's agricultural injury is warranted. Improved knowledge of the role of children's behaviors on their risk of 
agricultural injury could enhance current and future intervention efforts. The purpose of the current study was to analyze associations between reported behavioral traits among children ages six to $<20$ years and their risk of agricultural injury on family farming and ranching operations.

\section{Method}

\subsection{Overview}

This study was based on combined data from Phase 1 (JanuaryDecember, 1999) and Phase 2 (January-December, 2001) of the Regional Rural Injury Study-II (RRIS-II). The RRIS-II involved prospective, population-based cohort studies of agricultural households in Minnesota, North Dakota, South Dakota, Nebraska, and Wisconsin. For the current analysis, data from the two cohorts involving all ages, as well as nested case-control studies involving children less than 20 years of age, were used. The Institutional Review Board, Human Subjects Committee, at the University of Minnesota approved the protocol for both study phases and the current analyses.

\subsection{Study population}

The U.S. Department of Agriculture (USDA) National Agricultural Statistics Service Master ListFrame of Farming Operations provided the roster of farming and ranching operations. For each phase, random samples of 3,200 agricultural operations were selected for each of the five states, providing a total of 16,000 selected operations per year. To be eligible for the study, operations had to: (a) have a household associated with the operation that included children $<20$ years of age in residence as of January 1st of the respective study year; (b) produce at least $\$ 1,000$ of agricultural goods in the year prior to each study year, or be involved in a Conservation Reserve Program (CRP); and (c) be actively farming/ranching as of January 1st of the respective years.

\subsection{Data collection}

Subsequent to an introductory mailing in January of each study year, telephone interviews were conducted, using a computer assisted telephone interview (CATI) instrument, to obtain informed consent, establish eligibility, and enroll eligible households that were willing to participate in the study. Eligible participating households were mailed comprehensive packets of information containing: (a) cover letters from the study investigators and respective state USDA offices; and, (b) booklets with detailed information to facilitate telephone interviews, and logs to maintain ongoing information about injury events between January 1 st and June 30th. Comparable mailings were implemented for the second six months of data collection (July 1st - December 31st) in each study year.

Full-length CATI interviews began in July of each year (1999 and 2001), and January of the following years, to collect data for the respective prior six-month periods. The female head of household was the preferred informant for the collection of demographic, behavioral, and injury data, while the male head of household was preferred for operation information. Consent was requested to collect personal exposure information, including farming- and ranching-related work activities, directly from children who were 12 years of age and older; $21 \%$ of case-control children were their own respondents. The preferred respondent for children less than 12 years of age, and for children 12 and older for whom consent was not received (63\%), was the female head of household.

\subsection{Case and control selection}

Cases were all agricultural injury events associated with their own operation and sustained during the study years (1999 for Phase 1; 2001 for Phase 2 ) by children $<20$ years of age. An agricultural injury event had to result from farm- or ranch-related work activities or objects, and lead to restriction of normal activities for four hours or more, loss of consciousness or awareness, or amnesia, for any length of time, and/or treatment by a health professional. Case events were identified for each six-month reporting period prior to the full-length interviews (January - June, and July - December, of each year).

The case-control interviews, nested within the full-length interviews, collected behavior and exposure data for the month before the month of injury for cases, and the month before an agricultural injuryfree month for controls. The sampling of controls occurred during each of the full-length interviews and was based on an incidence-density sampling scheme. An algorithm was pre-programmed into the CATI system to ensure a minimum ratio of three controls per case. This was done by using injury incidence rates from the most recent, similar study to estimate the number of controls that should be sampled per month: Phase 1 selection was based on data from the Regional Rural Injury Study - I (RRIS-I) (Gerberich et al., 1993) while Phase 2 selection was based on Phase 1 data (Gerberich et al., 2003).

\subsection{Behavioral items and scales}

For case and control children ages six to $<20$ years, responses were elicited for 18 behavioral items adapted from commonly used, validated inventories; most were from the Parent Observation of Child Adaptation (POCA) checklist (Ialongo, Kellam, \& Podusk, 1999). Questions were in the form of a four-point Likert scale and addressed behaviors considered either desirable (completed work/chores; followed rules; worked hard; planned carefully before going ahead; was cautious; paid attention; had good concentration) or undesirable (acted without thinking; got into fights; was impulsive; broke rules; couldn't sit still; was easily distracted; was irritable; left the house or farm without permission; looked sad or down; bullied or was mean to others; had low energy).

These items were used to form behavioral scales relevant to the agricultural population. Hypothesized a priori constructs, based on POCA scales from which items were selected, were modified based on results of exploratory factor analysis (Field, 2000; Floyd \& Wideman, 1995). Maximum likelihood analyses with promax oblique rotations were performed using SPSS version 12.0 for Windows (SPSS, 2003). Resulting factors with eigenvalues greater than 1.0 and items with absolute values greater than 0.40 for factor loadings were retained for subsequent, iterative analyses. Cronbach's alphas were used to test internal consistency for resulting scales (Cronbach, 1951).

Five scales were developed using this approach: (a) Depression: Child looked sad or down; had low energy; was irritable (Cronbach's alpha =0.58); (b) Aggression: Child broke rules; got into fights; was impulsive (alpha $=0.51$ ); (c) Self-Regulation: Child was easily distracted; paid attention; had good concentration; worked hard (alpha $=0.78$ ); (d) Careful/Cautious: Child was careful; was cautious (alpha =0.58); and (e) Responsible Conduct: Child completed work; followed rules (alpha $=0.60$ ).

The individual behavioral items were dichotomized to allow comparisons of children who almost always/often exhibited the behavior and those who almost never/sometimes did. For the five scalar constructs, responses to the desirable behavioral items were reverse coded. Scores were then categorized to compare children with the least desirable level of the behavior (to the extent possible, those within the 10th percentile tail) to those with more moderate (10th to $<50$ th percentile) and desirable (50th to 100th percentile) levels.

\subsection{Data analysis}

Multivariable logistic regression was used to estimate risk of children's agricultural injury, in reference to behavioral items and scales, while controlling for potentially confounding variables (Breslow \& Day, 1987). Odds ratios (OR) and 95\% confidence intervals (CI) 
were calculated using logistic regression. Two models were analyzed: one estimated children's risk of injury while controlling for age and gender, and the second included additional potential confounders. To identify potential confounders, a causal model was used as a basis for the design and use of directed acyclic graphs (DAGs), following the methods described by Greenland, Pearl, and Robins (1999) and illustrated by Hernán, Hernández-Díaz, Werler, and Mitchell (2002). In short, the DAGs identified known or assumed causal associations between variables, thereby enabling specification of the most parsimonious statistical models. The DAGs also facilitated exclusion of covariates that could introduce bias if included in the models. The risk estimates for each behavioral item or scale were also adjusted for the other behavioral items or scales.

Odds ratios were adjusted for within-household correlation using generalized estimating equations (GEEs; Liang, \& Zeger, 1986). Potential selection bias from non-participation was controlled by inversely weighting observed responses with stratum-specific probabilities of response (Horvitz \& Thompson, 1952), estimated as a function of characteristics available from the NASS database (state in which the operation was located; type of operation; annual revenue by quintile). To account for unknown eligibility among non-respondents, probability of eligibility was estimated for these same characteristics and used to adjust weights (Mongin, 2001). Descriptive and regression analyses were performed with SAS version 9.1 for Windows.

\section{Results}

Based on comparable population characteristics and response rates between Phase 1 (1999) and Phase 2 (2001) of the RRIS-II (Gerberich et al., 2003, 2004), these data were combined for the current study. A

Table 1

Characteristics of cases and controls six to $<20$ years of age: Regional Rural Injury Study - II (RRIS-II)

\begin{tabular}{|c|c|c|c|c|}
\hline \multirow[t]{2}{*}{ Characteristic } & \multicolumn{2}{|c|}{$\begin{array}{l}\text { Cases } \\
(\mathrm{n}=379)\end{array}$} & \multicolumn{2}{|c|}{$\begin{array}{l}\text { Controls } \\
(n=1,562)\end{array}$} \\
\hline & $\bar{n}$ & $(\%)$ & $\bar{n}$ & $(\%)$ \\
\hline \multicolumn{5}{|l|}{ Gender } \\
\hline Male & 262 & $(69.1)$ & 873 & $(55.9)$ \\
\hline Female & 117 & $(30.9)$ & 689 & $(44.1)$ \\
\hline \multicolumn{5}{|l|}{ Age (years) } \\
\hline $6-<10$ & 55 & $(14.5)$ & 306 & $(19.6)$ \\
\hline $10-<14$ & 138 & $(36.4)$ & 419 & $(26.8)$ \\
\hline $14-<20$ & 186 & $(49.1)$ & 834 & $(53.4)$ \\
\hline Missing/Unknown/Refused & 0 & $(0.0)$ & 3 & $(0.2)$ \\
\hline \multicolumn{5}{|l|}{ Hours Worked/Week on Operation } \\
\hline$<10$ & 131 & $(34.6)$ & 962 & $(61.6)$ \\
\hline $10-<20$ & 88 & $(23.2)$ & 233 & $(14.9)$ \\
\hline $20-<30$ & 74 & $(19.5)$ & 149 & $(9.5)$ \\
\hline $30-<40$ & 22 & $(5.8)$ & 60 & (3.8) \\
\hline $40+$ & 45 & (11.9) & 103 & $(6.6)$ \\
\hline Missing/Unknown/Refused & 19 & $(5.0)$ & 55 & $(3.5)$ \\
\hline \multicolumn{5}{|l|}{ Parents' Average Age } \\
\hline$<35$ years & 32 & $(8.4)$ & 113 & $(7.2)$ \\
\hline $35-<45$ years & 234 & $(61.7)$ & 786 & $(50.3)$ \\
\hline $45-<55$ years & 101 & $(26.7)$ & 581 & $(37.2)$ \\
\hline $55+$ years & 12 & $(3.2)$ & 79 & $(5.1)$ \\
\hline Missing/Unknown/Refused & 0 & $(0.0)$ & 3 & $(0.2)$ \\
\hline \multicolumn{5}{|l|}{ Number of Children in Household } \\
\hline 1 & 61 & $(16.1)$ & 472 & $(30.2)$ \\
\hline 2 & 137 & $(36.2)$ & 546 & $(35.0)$ \\
\hline 3 & 101 & $(26.7)$ & 346 & $(22.2)$ \\
\hline $4+$ & 80 & $(21.1)$ & 195 & $(12.5)$ \\
\hline Missing/Unknown/Refused & 0 & $(0.0)$ & 3 & $(0.2)$ \\
\hline \multicolumn{5}{|l|}{ Type of Operation Requiring Most Time } \\
\hline Beef cattle & 110 & $(29.0)$ & 422 & $(27.0)$ \\
\hline Dairy cattle & 81 & $(21.4)$ & 201 & $(12.9)$ \\
\hline Other animals & 47 & $(12.4)$ & 154 & $(9.9)$ \\
\hline Field, forage, specialty crops; conservation reserve & 131 & $(34.6)$ & 740 & $(47.4)$ \\
\hline \multicolumn{5}{|c|}{ Program (CRP); or nothing during month of inquiry } \\
\hline Missing/Unknown/Refused & 10 & $(2.6)$ & 45 & $(2.9)$ \\
\hline
\end{tabular}

Table 2

Risk of agricultural injury among children aged six to $<20$ by behavioral items: Regional Rural Injury Study - II (RRIS-II)

\begin{tabular}{|c|c|c|c|c|c|}
\hline \multirow[t]{2}{*}{ Behavioral Item } & \multicolumn{2}{|c|}{$\begin{array}{l}\text { Cases } \\
\mathrm{n}=379\end{array}$} & \multicolumn{2}{|c|}{$\begin{array}{l}\text { Controls } \\
n=1,562\end{array}$} & \multirow{2}{*}{ 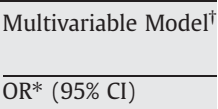 } \\
\hline & $\mathrm{n}$ & $(\%)$ & $\bar{n}$ & $(\%)$ & \\
\hline \multicolumn{6}{|l|}{ Acted Without Thinking } \\
\hline Almost Always/Often & 36 & $(9.7)$ & 151 & $(9.9)$ & $0.8(0.5-1.3)$ \\
\hline Almost Never/Sometimes & 336 & $(90.3)$ & 1372 & $(90.1)$ & Referent \\
\hline \multicolumn{6}{|l|}{ Was Impulsive } \\
\hline Almost Always/Often & 35 & $(9.4)$ & 138 & $(9.1)$ & $0.9(0.5-1.5)$ \\
\hline Almost Never/Sometimes & 336 & $(90.6)$ & 1383 & (90.9) & Referent \\
\hline \multicolumn{6}{|l|}{ Liked to Plan Carefully } \\
\hline Almost Never/Sometimes & 165 & $(44.4)$ & 580 & $(38.1)$ & $1.3(0.9-1.7)$ \\
\hline Almost Always/Often & 207 & $(55.6)$ & 942 & (61.9) & Referent \\
\hline \multicolumn{6}{|l|}{ Was Cautious } \\
\hline Almost Never/Sometimes & 88 & $(23.7)$ & 289 & $(19.0)$ & $1.6(1.1-2.3)$ \\
\hline Almost Always/Often & 284 & $(76.3)$ & 1235 & $(81.0)$ & Referent \\
\hline \multicolumn{6}{|l|}{ Couldn't Sit Still } \\
\hline Almost Always/Often & 56 & $(15.1)$ & 230 & $(15.1)$ & $0.9(0.6-1.3)$ \\
\hline Almost Never/Sometimes & 316 & $(84.9)$ & 1293 & $(84.9)$ & Referent \\
\hline \multicolumn{6}{|l|}{ Was Easily Distracted } \\
\hline Almost Always/Often & 37 & $(9.9)$ & 151 & $(9.9)$ & $0.9(0.6-1.6)$ \\
\hline Almost Never/Sometimes & 335 & (90.1) & 1375 & $(90.1)$ & Referent \\
\hline \multicolumn{6}{|l|}{ Paid Attention } \\
\hline Almost Never/Sometimes & 45 & $(12.1)$ & 216 & $(14.2)$ & $0.7(0.4-1.1)$ \\
\hline Almost Always/Often & 327 & $(87.9)$ & 1310 & $(85.8)$ & Referent \\
\hline \multicolumn{6}{|l|}{ Had Good Concentration } \\
\hline Almost Never/Sometimes & 57 & $(15.4)$ & 261 & $(17.1)$ & $0.8(0.5-1.3)$ \\
\hline Almost Always/Often & 314 & (84.6) & 1263 & (82.9) & Referent \\
\hline \multicolumn{6}{|l|}{ Followed Rules } \\
\hline Almost Never/Sometimes & 46 & $(12.4)$ & 141 & $(9.2)$ & $1.5(0.9-2.5)$ \\
\hline Almost Always/Often & 326 & $(87.6)$ & 1386 & $(90.8)$ & Referent \\
\hline \multicolumn{6}{|l|}{ Broke Rules } \\
\hline Almost Always/Often & 13 & $(3.5)$ & 32 & $(2.1)$ & $2.0(0.9-4.4)$ \\
\hline Almost Never/Sometimes & 359 & $(96.5)$ & 1495 & $(97.9)$ & Referent \\
\hline \multicolumn{6}{|l|}{ Left the Farm/House } \\
\hline Almost Always/Often & 14 & $(3.8)$ & 27 & $(1.8)$ & $1.4(0.6-3.2)$ \\
\hline Almost Never/Sometimes & 358 & $(96.2)$ & 1482 & (98.2) & Referent \\
\hline \multicolumn{6}{|l|}{ Completed Work/Chores } \\
\hline Almost Never/Sometimes & 27 & $(7.3)$ & 154 & $(10.1)$ & $0.9(0.5-1.6)$ \\
\hline Almost Always/Often & 342 & (92.7) & 1367 & $(89.9)$ & Referent \\
\hline \multicolumn{6}{|l|}{ Worked Hard } \\
\hline Almost Never/Sometimes & 36 & $(9.7)$ & 242 & $(15.9)$ & $0.6(0.3-0.9)$ \\
\hline Almost Always/Often & 336 & $(90.3)$ & 1282 & $(84.1)$ & Referent \\
\hline \multicolumn{6}{|l|}{ Got Into Fights } \\
\hline Almost Always/Often & 17 & $(4.6)$ & 39 & $(2.6)$ & $1.9(0.9-3.8)$ \\
\hline Almost Never/Sometimes & 355 & (95.4) & 1482 & $(97.4)$ & Referent \\
\hline Bullied Others & & & & & \\
\hline Almost Always/Often & 6 & $(1.6)$ & 19 & $(1.2)$ & $0.6(0.2-2.2)$ \\
\hline Almost Never/Sometimes & 366 & (98.4) & 1506 & (98.8) & Referent \\
\hline Had Low Energy & & & & & \\
\hline Almost Always/Often & 14 & $(3.8)$ & 38 & $(2.5)$ & $1.7(0.7-3.9)$ \\
\hline Almost Never/Sometimes & 357 & $(96.2)$ & 1488 & $(97.5)$ & Referent \\
\hline Looked Sad or Down & & & & & \\
\hline Almost Always/Often & 9 & $(2.4)$ & 22 & $(1.4)$ & $1.8(0.7-5.1)$ \\
\hline Almost Never/Sometimes & 362 & (97.6) & 1502 & (98.6) & Referent \\
\hline Was Irritable & & & & & \\
\hline Almost Always/Often & 24 & $(6.5)$ & 86 & $(5.6)$ & $0.9(0.5-1.8)$ \\
\hline Almost Never/Sometimes & 348 & (93.5) & 1440 & $(94.4)$ & Referent \\
\hline
\end{tabular}

* Adjusted for within-household correlation using GEEs (Liang and Zeger, 1986) and weighted for non-response (Horvitz and Thompson, 1952; Mongin, 2001).

${ }^{\dagger}$ Models included gender, age, body mass index, number of hours worked on operation, parents' average age, parents' highest education level, number of children in household, operation state, operation type, operation income, and 17 remaining behavioral items.

total of 8,810 (28\%) of the farms/ranches were found to be eligible. Of those, 7,420 (84\%) participated in the respective full study. In total, 379 eligible cases (95\%) and 1,562 eligible controls (97\%), ages six to $<20$, participated and were included in the analyses.

\subsection{Participant characteristics}

Demographic and exposure characteristics of cases and controls are presented in Table 1. Case versus control children were more likely 
to be males ( $70 \%$ vs. $56 \%$, respectively), have parents between the ages of 35 and 44 ( $62 \%$ vs. $50 \%$ ) as opposed to 45 and 54 (27\% vs. $37 \%$ ), reside in households with four or more children (22\% vs. $13 \%$ ), and reside in households associated with dairy cattle operations (22\% vs. $13 \%)$. Control children tended to work fewer hours than cases, with $63 \%$ versus $36 \%$ working $<10$ hours/ week, $14 \%$ versus $23 \%$ working 10 to $<20$ hours per week, and $9 \%$ versus $19 \%$ working 20 to $<30$ hours per week. No significant differences were observed in state of residence, children's body-mass index, parents' educational status, or operation income.

\subsection{Regression analyses}

\subsubsection{Behavioral items}

Results of multivariable regression analyses for behavioral items are presented in Table 2. Results were comparable between the model controlling for age and gender (data not shown), and the full multivariable model. Increased risks were identified for children who almost never/sometimes liked to plan carefully $(\mathrm{OR}=1.3$, $\mathrm{CI}=0.9-1.7)$, were cautious $(\mathrm{OR}=1.6, \mathrm{CI}=1.1-2.3)$, or followed rules $(\mathrm{OR}=1.5, \mathrm{CI}=0.9-2.5)$; as well as for children who almost always/often broke rules $(\mathrm{OR}=2.0, \mathrm{CI}=0.9-4.4)$ or got into fights $(\mathrm{OR}=1.9, \mathrm{CI}=0.9-3.8)$. Reduced risks were observed for children who almost never/sometimes worked hard $(\mathrm{OR}=0.6, \mathrm{CI}=0.3-0.9)$ or paid attention $(\mathrm{OR}=0.7, \mathrm{CI}=0.4-1.1)$.

\subsubsection{Behavioral scales}

Four behavioral scales (depression, aggression, self-regulation, and careful/cautious) were associated with children's risks of agricultural injury (Table 3). Children with high, versus low, levels of depressive

\section{Table 3}

Risk of agricultural injury among children aged six to $<20$ by behavioral scales: Regional Rural Injury Study - II (RRIS-II)

\begin{tabular}{|c|c|c|c|c|c|}
\hline \multirow[b]{2}{*}{ Behavioral Scale (items included) } & \multicolumn{2}{|c|}{$\begin{array}{l}\text { Cases } \\
\mathrm{n}=379\end{array}$} & \multicolumn{2}{|c|}{$\begin{array}{l}\text { Controls } \\
n=1,562\end{array}$} & \multirow{2}{*}{$\begin{array}{l}\text { Multivariable } \\
\text { Model }^{\dagger} \\
\mathrm{OR}^{*}(95 \% \mathrm{CI})\end{array}$} \\
\hline & $\bar{n}$ & $(\%)$ & $\mathrm{n}$ & $(\%)$ & \\
\hline \multicolumn{6}{|l|}{$\begin{array}{l}\text { Depressive Symptoms (looked sad or } \\
\text { down; had low energy; } \\
\text { was irritable) }\end{array}$} \\
\hline High & 25 & $(6.7)$ & 67 & $(4.4)$ & $1.9(1.0-3.7)$ \\
\hline Medium & 137 & $(36.8)$ & 583 & $(38.2)$ & $1.2(0.9-1.5)$ \\
\hline Low & 210 & $(56.5)$ & 876 & $(57.4)$ & Referent \\
\hline \multicolumn{6}{|l|}{$\begin{array}{l}\text { Aggression (broke rules; got into } \\
\text { fights; was impulsive) }\end{array}$} \\
\hline High & 30 & $(8.1)$ & 84 & $(5.5)$ & $1.6(0.9-2.7)$ \\
\hline Medium & 125 & $(33.6)$ & 486 & $(31.8)$ & $1.0(0.7-1.4)$ \\
\hline Low & 217 & $(58.3)$ & 957 & (62.7) & Referent \\
\hline \multicolumn{6}{|l|}{$\begin{array}{l}\text { Self-Regulation (was easily } \\
\text { distracted; had problems paying } \\
\text { attention; had good concentration; } \\
\text { worked hard) }\end{array}$} \\
\hline Low & 34 & $(9.1)$ & 167 & $(10.9)$ & $0.4(0.2-0.8)$ \\
\hline Medium & 133 & $(35.8)$ & 591 & $(38.7)$ & $0.7(0.5-1.0)$ \\
\hline High & 205 & $(55.1)$ & 769 & $(50.4)$ & Referent \\
\hline \multicolumn{6}{|l|}{$\begin{array}{l}\text { Careful/Cautious (was careful; } \\
\text { was cautious) }\end{array}$} \\
\hline Low & 80 & $(21.5)$ & 239 & $(15.7)$ & $1.8(1.1-2.9)$ \\
\hline Medium & 127 & $(34.1)$ & 554 & (36.3) & $1.0(0.7-1.4)$ \\
\hline High & 165 & $(44.4)$ & 733 & $(48.0)$ & Referent \\
\hline \multicolumn{6}{|l|}{$\begin{array}{l}\text { Responsible Conduct (completed } \\
\text { work; followed rules) }\end{array}$} \\
\hline Low & 34 & $(9.1)$ & 135 & $(8.8)$ & $1.2(0.7-2.1)$ \\
\hline Medium & 123 & (33.1) & 448 & $(29.3)$ & $1.2(0.8-1.6)$ \\
\hline High & 215 & $(57.8)$ & 944 & $(61.9)$ & Referent \\
\hline
\end{tabular}

* Adjusted for within-household correlation using GEEs (Liang and Zeger, 1986) and weighted for non-response (Horvitz and Thompson, 1952; Mongin, 2001).

† Models included gender, age, body mass index, number of hours worked on operation, parents' average age, parents' highest education level, number of children in household, operation state, operation type, operation income, and four remaining behavioral scales. symptoms had nearly twice the risk of injury ( $\mathrm{OR}=1.9, \mathrm{CI}=1.0-3.7)$ as did those with low levels of careful/cautious behavior $(\mathrm{OR}=1.8$, $\mathrm{CI}=1.1-2.9)$. High scores for aggression also appeared to be associated with elevated risk $(\mathrm{OR}=1.6, \mathrm{CI}=0.9-2.7)$. Contrarily, low and medium levels of self-regulation were associated with reduced risks of injury $(\mathrm{OR}=0.4, \mathrm{CI}=0.2-0.8$ and $\mathrm{OR}=0.7, \mathrm{CI}=0.5-1.0$, respectively).

\section{Discussion}

Rural agricultural households comprise a unique population due to distinct socio-cultural factors, hazardous exposures, and high rates of occupational injury, particularly among children. While previous studies have identified behavioral traits as potential risk factors for injury, this study is distinct in that it explores behavioral factors that may contribute to the risk of agricultural injury among children in farming and ranching households.

Results showed that children's behaviors were associated with their risk of agricultural injury, though not always in the predicted direction. Increased risks of injury were identified for children who were less cautious, less likely to plan carefully, or less likely to follow rules. Reduced risks were observed for those who were less likely to work hard or pay attention. Elevated risks were also identified for children with high levels of depressive symptoms, aggression, and self-regulation, and for those with low levels for being careful/ cautious.

Though some of the behavioral constructs examined appeared to play a unique role in this population, these results were generally consistent with prior studies of behavior and injury. Across past studies, aggression has been shown to be positively associated with risk of injury, particularly among children (Bijur et al., 1986; Manheimer \& Mellinger, 1967). For example, a study of medicallytreated, unintentional injuries among nearly 12,000 preschool children showed those in the 90th percentile of aggression scores to have elevated risks for hospitalized and non-hospitalized injuries (Bijur et al., 1986). In the current study, children who exhibited high levels of aggression had increased risk for agricultural injury, compared to children with low aggression levels. This association may be due to increased risk-taking among those with aggressive personalities (Zuckerman \& Kuhlman, 2000) which, on agricultural operations, could lead to more high-risk exposures than among children with lower tolerance for risk.

An interesting finding from this study was the association between agricultural injuries and symptoms of depression. Children in the highest 10th percentile of depression-related scores had twice the risk as children with the lowest scores (50th to 100th percentile). Depressive symptoms have been shown to be associated with poor safety practices in an agricultural population (Stallones \& Beseler, 2004). To date, though, there has been limited statistical evidence of associations between depression and risk of unintentional injury. One exception is a study by Park et al. (2001), which found that depressive symptoms were associated with risk of agricultural injuries among male principal farm owners. The current finding, pertinent to children of farming and ranching families, is notable and should be taken into context with the documented prevalence of depressive symptoms in the agricultural population (Linn \& Husaini, 1987; Scarth, Stallones, Zwerling, \& Burmeister, 2000; Stallones, Leff, Garrett, Criswell, \& Gillan, 1995).

While not considered in this study, there is a current, growing interest in the associations between adolescent sleep and health, including injury. Prior studies have shown inadequate sleep and variant sleep patterns to be associated with increased risks of injury among children and adolescents (Koulouglioti, Cole, \& Kitzman, 2008; Valent, Brusaferro, \& Barbone, 2001), including those residing on family farms (Stallones, Beseler, \& Chen, 2006). Sleep and sleepiness have also been shown to be associated with children's behaviors (Gregory, Eley, O'Connor, \& Plomin, 2004; Lavigne et al., 1999) and 
could potentially confound identified associations between behavioral traits and injury. Therefore, it would be worthwhile to explore the interrelatedness of these factors, potentially controlling for sleep quantity and quality in future studies of behavior and injury among children.

Individual items as well as the averaged score for careful/cautious behavior were strongly associated with reduced risks of agricultural injury. These results were not surprising, since prior research suggests that children who are "planful," or controlled and deliberate in their actions, are less likely to engage in impulsive, risk-taking behavior (Caspi \& Silva, 1995). On agricultural operations, children with conscientious, or careful/cautious, personalities might have decreased risks for a multitude of reasons. For example, these children might make use of current educational materials aimed at reducing risk of agriculture-related injury.

Though conclusions have been highly inconsistent, hyperactivity has been examined readily as a potential risk factor for children's injury (Davidson, 1987). Four items that comprise many hyperactivity scales (couldn't sit still; impulsive; acted without thinking; had good concentration) did not factor together in the current analyses, which suggests a distinct construct for these items within the agricultural community. The fact that the four individual items were not associated with injury seems to be consistent with most recent findings. While prior studies have shown activity-related measures to be associated with children's injury (Bijur et al., 1986; Langley, McGee, Silva, \& Williams, 1983; Manheimer \& Mellinger, 1967), findings from a more recent, prospective cohort study found no association between injury and hyperactivity (Davidson, 1992).

On the contrary, factor analysis identified four items (child was easily distracted; had problems paying attention; had good concentration; worked hard) that were strongly related, with a Cronbach's alpha of 0.78; this factor was referred to as children's self-regulation. A novel and important finding from this study was that children with low levels of self-regulation were at half the risk of agricultural injury as children with high scores for this construct. This is counter to previous suggestion that poor self-regulation is associated with risktaking (Steinberg, 2004), and a past study showing poor self-control to be associated with injury (Manheimer \& Mellinger, 1967). Reasons for this surprising finding may include that parents supervise children with poor attention skills more closely, or that parents, aware of attention problems in their children, assign less hazardous or challenging work to children they know to be distractible. Concomitantly, parents may be more likely to entrust children with good attention skills to chores they believe require better concentration.

Further findings in this paper appear to reflect children's differential assignment to farm or ranch chores. For example, the item "child worked hard," appeared to play an important and distinct role in this particular study population. Working hard is, in general, a positive trait and was therefore expected to be inversely associated with injury. Interestingly, a direct association was observed; children who almost never/sometimes worked hard had reduced risks of injury. While work hours were controlled in the regression analysis, residual confounding due to differential work pace or work exposures might explain this association. Nonetheless, agricultural operations appear to present a unique context in which parent perceptions of individual child behavior, and the nature of work available to children, interact in complex ways. Future research examining potential associations between children's behavioral traits and their specific environmental exposures could further elucidate the causal pathway between children's behaviors and injuries.

\subsection{Strengths and limitations}

While this study addresses a deficiency in current knowledge about children's behavioral traits and agricultural injury, results should be interpreted in light of study limitations. Analyses of behavioral items and injury data may have been susceptible to recall bias. This issue is relevant to results pertinent to depression, given that these symptoms are commonly a result of injury (Keogh, Nuwayhid, Gordon, \& Gucer, 2000); but, concern may also extend to other behavioral items and scales. To address this potential bias, along with further measurement and selection issues, multiple measures were taken. Based on prior validation efforts (Braun, Gerberich, \& Sidney, 1994; Gerberich et al., 1990), injury data were collected for six-month windows to limit information bias. Additionally, behavior-related items were measured in reference to the months prior to the injury events for cases, or randomly selected months for controls. Limited data pertinent to agricultural operation state, size, and annual revenue by quintile were also used in aggregate form to identify and adjust for differences in response among households.

While the multivariable analyses controlled for a number of important potential confounders, including operation type, operation income, parents' education levels, and number of hours worked on the operation, the potential for an additional, unmeasured confounder cannot be ruled out. For example, parenting factors, such as supervision, could explain some children's behaviors and also affect their risk of injury (Morrongiello, Corbett, McCourt, \& Johnston, 2006). Unfortunately, some variables that would be useful for the current analyses, such as parental supervision, or children's sleep quality, could not be included in the survey instrument due to the length of administration time. These potential confounders should be evaluated in future studies.

Given that a main intent of the RRIS-II was to serve as a tool for surveillance of environmental risk factors for agricultural injury, the behavioral items measured also had to be limited in scope and number. The 18 items used were selected based on their deemed relevance to work and safety on agricultural operations. The a priori constructs, based mostly on the questionnaires from which the items were adapted, were modified based on results of exploratory factor analyses to yield the scales that were used. However, apart from selfregulation, Cronbach's alphas for each scale were relatively low. Low alphas may have resulted in part from the limited number of items included in each scale, but may also indicate limited interpretability of these latent behavioral constructs.

\section{Summary}

To date, there has been limited understanding of the impact of children's behavioral characteristics on their risk of unintentional injury. This study identified several behaviors as potential risk factors for injury and, paradoxically, showed that children with attention and concentration problems (low self-regulation) had decreased risks. This and other findings imply that assignment of work to children on farms and ranches may be related to children's behavior. Future research on the procedures by which children are assigned certain chores on family operations, specifically, the role of behavioral and developmental differences in parents' decision-making about when particular children are ready to work, the chores they are ready to perform, and the levels of supervision they require, could enhance intervention efforts.

\section{Acknowledgments}

Support for this effort was provided by the National Institute for Occupational Safety and Health (NIOSH), Centers for Disease Control and Prevention, Department of Health and Human Services (R01 CCR514375; R01 OH04270); the Occupational Injury Prevention Research Training Program and the National Occupational Research Agenda Program, Midwest Center for Occupational Health and Safety, University of Minnesota (NIOSH T42/CCT510-422); and the Regional Injury Prevention Research Center and Center for Violence Prevention and Control, Division of Environmental Health Sciences, School of Public Health, University of Minnesota. The contents of this effort are 
solely the responsibility of the authors and do not necessarily represent the official view of the $\mathrm{CDC}$ or other associated entities.

The authors are grateful to the U.S. Department of Agriculture's National Agricultural Statistics Service for collaboration on this project. Furthermore, we are indebted to the farm and ranch families who shared their time and personal information during participation in the RRIS-II.

\section{References}

Bijur, P. E., Stewart-Brown, S., \& Butler, N. (1986). Child behavior and accidental injury in 11,966 preschool children. American Journal of Diseases of Children, 140(5), 487-492.

Braun, B. L., Gerberich, S. G., \& Sidney, S. (1994). Injury events: Utility of self-report in retrospective identification in the USA. Journal of Epidemiology and Community Health, 48(6), 604-605.

Breslow, N. E., \& Day, N. E. (1987). Statistical methods in cancer research. Volume II - the design and analysis of cohort studies. IARC Scientific Publications, 82, 1-406.

Caspi, A., \& Silva, P. A. (1995). Temperamental qualities at age three predict personality traits in young adulthood: Longitudinal evidence from a birth cohort. Child Development, 66(2), 486-498.

Cronbach, L. J. (1951). Coefficient alpha and the internal structure of tests. Psychometrika, 16, 297-334.

Davidson, L. L. (1987). Hyperactivity, antisocial behavior, and childhood injury: A critical analysis of the literature. Developmental and Behavioral Pediatrics, 8(6), $335-340$.

Davidson, L. L. (1992). Hyperactivity in school-age boys and subsequent risk of injury. Pediatrics, 90(5), 697-702

DeRoo, L. A., \& Rautiainen, R. H. (2000). A systematic review of farm safety interventions. American Journal of Preventive Medicine, 18(4 Suppl), 51-62.

Elder, G. H., Jr., \& Conger, R. D. (2000). Children of the Land. Adversity and Success in Rural America. Chicago, IL: University of Chicago Press.

Field, A. (2000). Discovering Statistics Using SPSS for Windows. Exploratory Factor Analysis. London: Sage Publications.

Floyd, F. J., \& Wideman, K. F. (1995). Factor analysis in the development and refinement of clinical assessment instruments. Psychological Assessment, 7, 286-289.

Gerberich, S. G., Alexander, B. H., Church, T. R., Masten, A. S., Renier, C. M., Mongin, S. J., et al. (2004). Regional Rural Injury Study - II, Phase 2: Agricultural Injury Surveillance. A report to the Centers for Disease Control and Prevention. Minneapolis: Regional Injury Prevention Center, University of Minnesota.

Gerberich, S. G., Gibson, R. W., French, L. D., Carr, P., Renier, C. M., Gunderson, P., et al. (1993). The Regional Rural Injury Study - I (RRIS-I): A population-based effort. A Report to the Centers for Disease Control and Prevention. Minneapolis: Regional Injury Prevention Center, University of Minnesota.

Gerberich, S. G., Gibson, R. W., French, L. R., Church, T. R., Alexander, B. H., Shutske, J., et al (2003). Etiology and consequences of injuries among children in farm households: A regional rural injury study. A report to the Centers for Disease Control and Prevention. Minneapolis: Regional Injury Prevention Center, University of Minnesota.

Gerberich, S. G., Gibson, R. W., French, L. R., Renier, C. M., Lee, T. -Y., Carr, W. P., et al. (2001). Injuries among farm children and youth in farm households: Regional Rural Injury Study-I (RRIS-I). Injury Prevention, 7(2), 117-122.

Gerberich, S. G., Gibson, R. W., Gunderson, P. W., Melton, L. J., III, French, L. R., Renier, C. M., et al. (1990). Validity of trauma reporting in the agricultural community. Journal of Occupational Accidents, 12, 200

Gregory, A. M., Eley, T. C., O'Connor, T. G., \& Plomin, R. (2004). Etiologies of associations between childhood sleep and behavioral problems in a large twin sample. Journal of the American Academy of Child and Adolescent Psychiatry, 43(6), 744-751.

Goldcamp, M., Hendicks, K. J., \& Myers, J. R. (2004). Farm fatalities to youth 1995-2000: A comparison by age groups. Journal of Safety Research, 35, 151-157.

Greenland, S., Pearl, J., \& Robins, J. M. (1999). Causal diagrams for epidemiologic research. Epidemiology, 10(1), 37-48

Hartling, L., Brison, R. J., Crumley, E. T., Klassen, T. P., \& Pickett, W. (2004). A systematic review of interventions to prevent childhood farm injuries. Pediatrics, 114(4), e483-e496.

Hendricks, K. J., Layne, L. A., Goldcamp, E. M., \& Myers, J. R. (2005). Injuries to youth living on U.S. farms in 2001 with comparison to 1998. Journal of Agromedicine, 10(4), 19-26.

Hernán, M. A., Hernández-Díaz, S., Werler, M. M., \& Mitchell, A. A. (2002). Causal knowledge as a prerequisite for confounding evaluation: An application to birth defects epidemiology. American Journal of Epidemiology, 155(2), 176-184

Horvitz, D. G., \& Thompson, D. J. (1952). A generalization of sampling without replacement from a finite universe. Journal of the American Statistical Association, 47 (260), 663-685.

Ialongo, N. S., Kellam, S. G., \& Poduska, J. (1999). Manual for the Parent Observation of Child Adaptation (Tech. Rep. No. 3). Baltimore, MD: Johns Hopkins University.

Jaquess, D. L., \& Finney, J. W. (1994). Previous injuries and behavior problems predict children's injuries. Journal of Pediatric Psychology, 19(1), 79-89.

Keogh, J. P., Nuwayhid, I., Gordon, J. L., \& Gucer, P. W. (2000). The impact of occupational injury on injured worker and family: outcomes of upper extremity cumulative trauma disorders in Maryland workers. American Journal of Industrial Medicine, 38(5), 498-506.

Kim, J., \& Zepeda, L. (2004a). Factors affecting children's participation and amount of labor on family farms. Journal of Safety Research, 35(4), 391-401.

Kim, J., \& Zepeda, L. (2004b). When the work is never done: Time allocation in US family farm households. Feminist Economics, 10(1), 115-139.

Koulouglioti, C., Cole, R., \& Kitzman, H. (2008). Inadequate sleep and unintentional injuries in young children. Public Health Nursing, 25(2), 106-114.
Langley, J., McGee, R., Silva, P., \& Williams, S. (1983). Child behavior and accidents. Journal of Pediatric Psychology, 8(2), 181-189.

Lavigne, J. V., Arend, R., Rosenbaum, D., Smith, A., Weissbluth, M., Binns, H. J., et al. (1999). Sleep and behavior problems among preschoolers. Journal of Developmental and Behavioral Pediatrics, 20(3), 164-169.

Linn, J. G., \& Husaini, B. A. (1987). Determinants of psychological depression and coping behaviors of Tennessee farm residents. Journal of Community Psychology, 15(4), 503-512.

Lee, B. C., Jenkins, L. S., \& Westaby, J. D. (1997). Factors influencing exposure of children to major hazards on family farms. Journal of Rural Health, 13(3), 206-215.

Liang, K. -Y., \& Zeger, S. L. (1986). Longitudinal data analysis using generalized linear models. Biometrika, 73, 13-22.

Manheimer, D. I., \& Mellinger, G. D. (1967). Personality characteristics of the child accident repeater. Child Development, 38(2), 491-513.

Mongin, S. J. (2001). Adjustment for non-response in the Minnesota Nurses Study. Health Studies Research Report. Minneapolis: Division of Environmental Health Sciences, University of Minnesota (http://enhs.umn.edu/research/pdfs/response.adjustment.1.pdf).

Morrongiello, B. A., Corbett, M., McCourt, M., \& Johnston, N. (2006). Understanding unintentional injury risk in young children II. The contribution of caregive supervision, child attributes, and parent attributes. Journal of Pediatric Psychology, 31(6), 540-551.

National Safety Council [NSC]. (2007). Injury Facts, 2007 Edition. Itasca, IL: Author

Park, H., Sprince, N. L., Lewis, M. Q., Burmeister, L. F., Whitten, P. S., \& Zwerling, Z. (2001) Risk factors for work-related injury among male farmers in Iowa: A prospective cohort study. Journal of Occupational and Environmental Medicine, 43(6), 542-547.

Rivara, F. P. (1997). Fatal and nonfatal farm injuries to children and adolescents in the United States, 1990-1993. Injury Prevention, 3(3), 190-194.

Scarth, R., Stallones, L., Zwerling, C., \& Burmeister, L. (2000). The prevalence of depressive symptoms and risk factors among Iowa and Colorado farmers. American Journal of Industrial Medicine, 37(4), 382-389.

Schwebel, D. C., \& Plumert, J. M. (1999). Longitudinal and concurrent relations among temperament, ability estimation, and injury proneness. Child Development, 70(3), $700-712$

SPSS (2003). SPSS: Version 12.0 for Windows. Chicago: Author.

Stallones, L., \& Beseler, C. (2004). Safety practices and depression among farm residents. Annals of Epidemiology, 14(8), 571-578.

Stallones, L., Beseler, C., \& Chen, P. (2006). Sleep patterns and risk of injury among adolescent farm residents. American Journal of Preventive Medicine, 30(4), 300-304.

Stallones, L., Leff, M., Garrett, C., Criswell, L., \& Gillan, T. (1995). Depressive symptoms among Colorado farmers. Journal of Agricultural Safety and Health, 1(1), 37-43.

Steinberg, L. (2004). Risk taking in adolescence: What changes, and why? Annals of the New York Academy of Sciences, 1021, 51-58.

Valent, F., Brusaferro, S., \& Barbone, F. (2001). A case-crossover study of sleep and childhood injury. Pediatrics, 107(2), E23.

Wazana, A. (1997). Are there injury-prone children? A critical review of the literature. Canadian Journal of Psychiatry, 42(6), 602-610.

Zuckerman, M., \& Kuhlman, D. M. (2000). Personality and risk-taking: Common biosocial factors. Journal of Personality, 68(6), 999-1029.

Kathleen F. Carlson Dr. Carlson completed her BS in Biology at Oregon State University, and her MS and $\mathrm{PhD}$ in Environmental Health at the University of Minnesota, Minneapolis, Minnesota. She is currently a Research Investigator with the Center for Chronic Disease Outcomes Research, Minneapolis VA Medical Center where she studies polytrauma and blast-related injuries, traumatic brain and spinal cord injury, and post-traumatic stress disorder among veterans. Her research interests also include injury prevention and control, occupational epidemiology, medical records injury coding, and health services for traumatic injury.

Susan Goodwin Gerberich Dr. Gerberich's educational background includes: BS in Nursing; MSPH, Public Health; PhD, Environmental Health - University of Minnesota Minneapolis, Minnesota. She has been on faculty in the School of Public Health since 1980 and is currently a Mayo Professor in the School of Public Health, Environmenta Health Sciences, University of Minnesota. Her research interests include: populationbased research and surveillance efforts that focus on injury epidemiology and control: injuries, in general; work-related, including agricultural injuries; brain and spinal cord injuries; violence; drug/alcohol use and injury consequences; sports injuries; and transportation-related injuries.

Bruce H. Alexander Dr. Alexander completed BS and MS degrees in Environmental Health at Colorado State University, Fort Collins, Colorado, and a PhD degree in Epidemiology at the University of Washington, Seattle. He has been a faculty member in the Division of Environmental Health Sciences, School of Public Health, University of Minnesota, since 1998 where he is currently an Associate Professor. His research interests include population-based studies of chronic disease as well as various injury epidemiology efforts.

Ann S. Masten Dr. Masten is Distinguished McKnight University Professor in Child Development and Psychology at the University of Minnesota. She completed her AB at Smith College and her PhD in clinical psychology at the University of Minnesota, with a psychology internship at the Neuropsychiatric institute at UCLA. She has been on the faculty of the Institute of Child Development at Minnesota since 1986, serving as Director from 1999-2005. Her research focuses on processes of competence, risk, and resilience in human development and translational implications of risk and resilience research for interventions to promote positive development. 
Timothy R. Church Dr. Church has an MS in Biometry and Health Information Systems and a PhD in Biostatistics (Biometry) from the University of Minnesota. He has been on the faculty of the University of Minnesota since 1996, and is currently a Professor in Environmental Health Sciences. He manages several large clinical centers for cancer screening research and is a member of the Cancer Center at the University of Minnesota. Besides injury and violence prevention, his research interests include statistical and epidemiologic methodology, cancer etiology, prevention, and early detection, screening for chronic disease, cardiac electrophysiology, and air quality research.

John M. Shutske Dr. Shutske's PhD is from Purdue University, focused on agricultural safety and health issues within the field of agricultural engineering. He currently is an Associate Dean for Extension and Outreach in the College of Agricultural and Life Sciences at the University of Wisconsin - Madison. Previously, Dr. Shutske served as Professor in the University of Minnesota's Department of Bioproducts and Biosystems Engineering at the University of Minnesota. During that time, he also served as an Agricultural Safety and Health Specialist with the University of Minnesota Extension Service, where he had frequent contact with agricultural worker audiences nationwide through his teaching and writing. Dr. Shutske's research interests have included agricultural injury risk factor investigation; development of safe designs/safeguards for agricultural production systems; influence of developmental factors on childhood injury; and development of educational programs in workplace safety that consider cultural, linguistic, and ethnic differences among worker populations.
Andrew D. Ryan Mr. Ryan completed a BSc degree in Industrial Microbiology at University College Dublin, Ireland and an MS in Plant Pathology at the University of Minnesota. Since 2000, he has served as a statistical programmer and analyst for numerous studies in the Division of Environmental Health Sciences, School of Public Health, University of Minnesota; since 2006, he has also served as a project director for a major five-state agricultural injury study.

Colleen M. Renier Ms. Renier's educational background includes a BS in Mathematical Statistics and Chemistry, University of Minnesota Duluth, Duluth, Minnesota. Since 1998 she has been employed as a Biostatistician/Statistical Programmer/Analyst in the Division of Education and Research, St. Mary's Duluth Clinic Health System, Duluth, Minnesota and has collaborated with Dr. Gerberich and colleagues on various research efforts since the mid-1980's. Her research interests and efforts encompass both clinical research and population-based efforts in many areas that include agricultural injury research and quality of life research. 